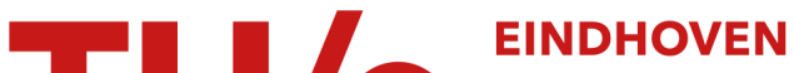 UNIVERSITY OF TECHNOLOGY
}

\section{Use of polarization in InP-based integrated optics}

\section{Citation for published version (APA):}

van der Tol, J. J. G. M., Augustin, L. M., Kok, A. A. M., Khalique, U., \& Smit, M. K. (2008). Use of polarization in InP-based integrated optics. In 2008 Conference on Quantum Electronics and Laser Science Conference on Lasers and Electro-Optics, CLEO/QELS (pp. CThM3-1/2). [4551484] Optical Society of America (OSA). https://doi.org/10.1109/CLEO.2008.4551484

DOI:

10.1109/CLEO.2008.4551484

Document status and date:

Published: 15/09/2008

\section{Document Version:}

Publisher's PDF, also known as Version of Record (includes final page, issue and volume numbers)

\section{Please check the document version of this publication:}

- A submitted manuscript is the version of the article upon submission and before peer-review. There can be important differences between the submitted version and the official published version of record. People interested in the research are advised to contact the author for the final version of the publication, or visit the $\mathrm{DOI}$ to the publisher's website.

- The final author version and the galley proof are versions of the publication after peer review.

- The final published version features the final layout of the paper including the volume, issue and page numbers.

Link to publication

\section{General rights}

Copyright and moral rights for the publications made accessible in the public portal are retained by the authors and/or other copyright owners and it is a condition of accessing publications that users recognise and abide by the legal requirements associated with these rights.

- Users may download and print one copy of any publication from the public portal for the purpose of private study or research.

- You may not further distribute the material or use it for any profit-making activity or commercial gain

- You may freely distribute the URL identifying the publication in the public portal.

If the publication is distributed under the terms of Article $25 f a$ of the Dutch Copyright Act, indicated by the "Taverne" license above, please follow below link for the End User Agreement:

www.tue.nl/taverne

Take down policy

If you believe that this document breaches copyright please contact us at:

openaccess@tue.nl

providing details and we will investigate your claim. 


\title{
Use of Polarization in InP-based Integrated Optics
}

\author{
J.J.G.M. van der Tol, L.M. Augustin, A.A.M. Kok, U. Khalique and M.K. Smit (1) \\ (1) COBRA Institute, Eindhoven University of Technology, P.O.Box 513, 5600MB Eindhoven, The Netherlands, phone +31 40247 5134, fax \\ +31402455197, email j.j.g.m.v.d.tol@tue.nl
}

\begin{abstract}
The development of integrated polarization manipulating devices opens the perspective on the use of polarization as a new design dimension in InP-based integrated optics. Examples will be given of how this results in additional functionalities. (C) 2008 Optical Society of America

OCIS codes: (130.0130) Integrated Optics; (130,5440) Polarization selective devices; (250.0250)

Optoelectronics; (250.3140) Integrated Optoelectronic circuits; (250.5300) Photonic integrated circuits.
\end{abstract}

\section{Introduction}

Photonic integrated circuits (PICs) have been struggling with the polarization aspects of light. The planar geometry of the waveguides creates a birefringent medium: propagation is different for TE and TM polarized modes. On the other hand, the polarized modes are very stable. This implies that polarization can be used for enhancement of functionality. Several examples of this are given. We concentrate on InGaAsP/InP, the material most suitable for photonic integration for use at telecom relevant wavelengths.

\section{Polarization manipulating devices}

The relative strength of the polarized modes can be controlled with polarization converters and polarization splitters/filters. Here we will introduce a complete set of basic building blocks for polarization handling.

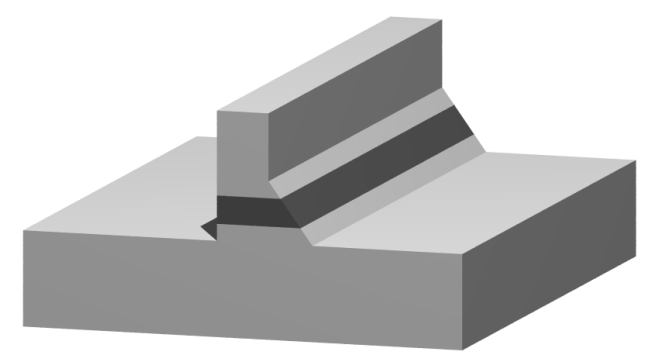

Fig. 1: A passive polarization converter, [1]. The converter length is about $125 \mu \mathrm{m}$. Conversions above $97 \%$ can be obtained in devices with $<3 \mathrm{~dB}$ loss.

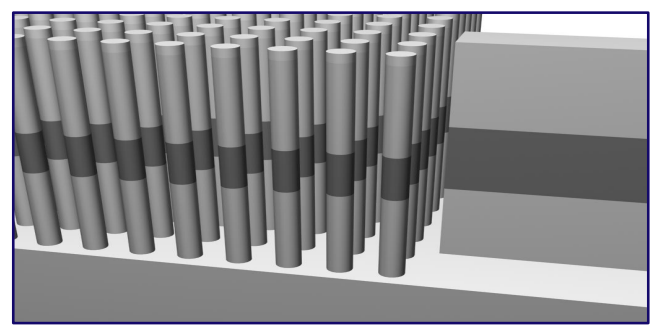

Fig. 3: Polarization filter based on photonic crystal pillars, with coupled ridge waveguide [3].

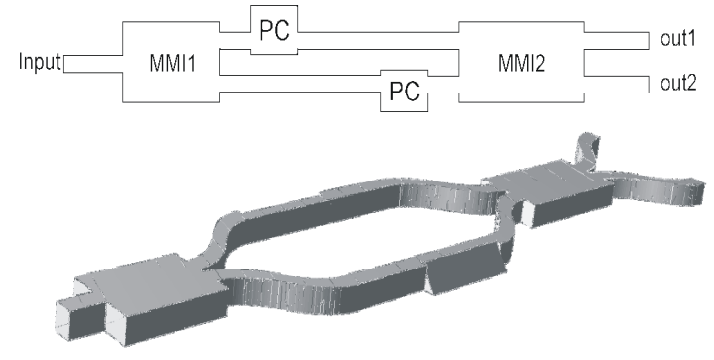

Fig. 2: Top view and schematic of the polarization splitter, based on an MZI with polarization converters (fig. 1) in the branches [2].

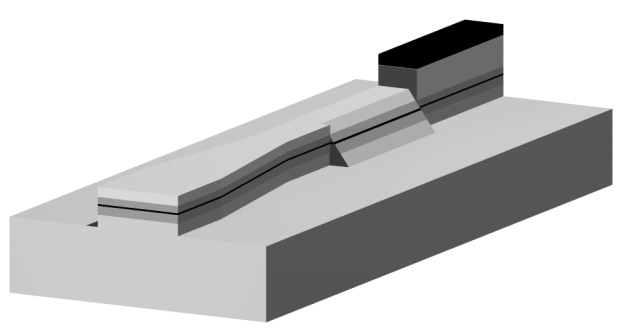

Fig. 4: Integrated waveguide and detector within POLIS. (input waveguide, taper, polarization converter (see fig. 1) and detector.)[4]

Polarization converter: Polarization conversion can be obtained with a narrow waveguide having one slanted sidewall (fig. 1, which shows a device designed for integratability [1]). This rotates the polarization of modes by $45^{\circ}$. A TE (or TM) mode from a symmetric input waveguide, equally excites the two rotated orthogonal modes then. These modes propagate with different propagation constants $\beta_{1}$ and $\beta_{2}$. After half of the beat length $\left(\mathrm{L}_{\lambda / 2}=\right.$ $\pi / 2\left(\left|\beta_{1}-\beta_{2}\right|\right)$ ) the rotated modes recombine to a TM (or TE) mode in a symmetric output waveguide. In this way full conversion between TE and TM is possible. Recently some other polarization converters have been published, which promise even shorter devices [5] or single mask fabrication [6].

Polarization splitter: Our polarization splitter (fig. 2, [2]) consists of a Mach-Zehnder interferometer with polarization converters in the branches. This creates a polarization dependent phase difference between the branches, which is used for polarization splitting. A splitting ratio of $10 \mathrm{~dB}$ has been demonstrated.

Polarization filter: For a very pure state of polarization in high performance applications filtering of the polarization is needed. The polarization splitters can be used for this, but they are rather bulky and have 


\section{CThM3.pdf}

difficulty achieving high extinction. A short and high-extinction polarization filter is realized with photonic crystals[3]. We developed a TE-filter based on pillar photonic crystal (fig. 3), which is compatible with the layer stack and processing of PICs. A photonic crystal waveguide was realized which supports propagation of only the TM-mode. A $4 \mu \mathrm{m}$ long device provides $20 \mathrm{~dB}$ extinction.

\section{Applications using polarization}

The possibility to control the polarization can be used to create additional functionality. Here we show three examples of this: a) polarization used to define active and passive functions, b) polarization used to distinguish different signals, and c) polarization used to create two independent optical paths within a waveguide.

a) POLarization based Integration Scheme (POLIS, fig. 4) In strained QWs there is a spectral region where change of polarization implies change from transparency (for TM) to absorption (for TE). This is the basis of POLIS, [4]. Polarization defines the active or passive sections, which are coupled with polarization converters. Only one growth step is needed. The circuit is flexible regarding the position of active and passive regions. The first POLIS integration combines a passive waveguide (propagating TM), a polarization converter and a photo detector (detecting TE, fig. 4). An external responsivity of $0.234 \mathrm{~A} / \mathrm{W}$ is measured, (uncorrected for coupling losses, $5 \mathrm{~dB}$ ). The dark current is a few nanoamperes. The absorption length is below $230 \mu \mathrm{m}$; short enough to allow detection at frequencies $>10 \mathrm{GHz}$.

b) POlarization LAbelling for Rejection and Isolation of Signals (POLARIS, fig. 5) A Mach-Zehnder Interferometer (MZI) with SOAs in the arms can be used for wavelength conversion. A pump signal, carrying information bits, is coupled into one arm, which causes cross phase modulation on a probe signal traveling through the MZI. This results in the bit pattern being inscribed on the output probe signal. The pump signal is however still present in the output. Counter directional propagation avoids this, but deteriorates the operation. Wavelength filtering leads to loss of flexibility. The POLARIS solution [7] allows for fully flexible optical networking. It is a polarization diversity scheme, in which the pump has an arbitrary polarization, while the probe signal is in a fixed polarization state. The pump and probe signals are manipulated to have opposite polarization states when interacting in the MZIs. Therefore, the two can be separated with a polarization splitter/combiner. The whole scheme is shown in fig. 5. Tests were done with integrated wavelength converters.

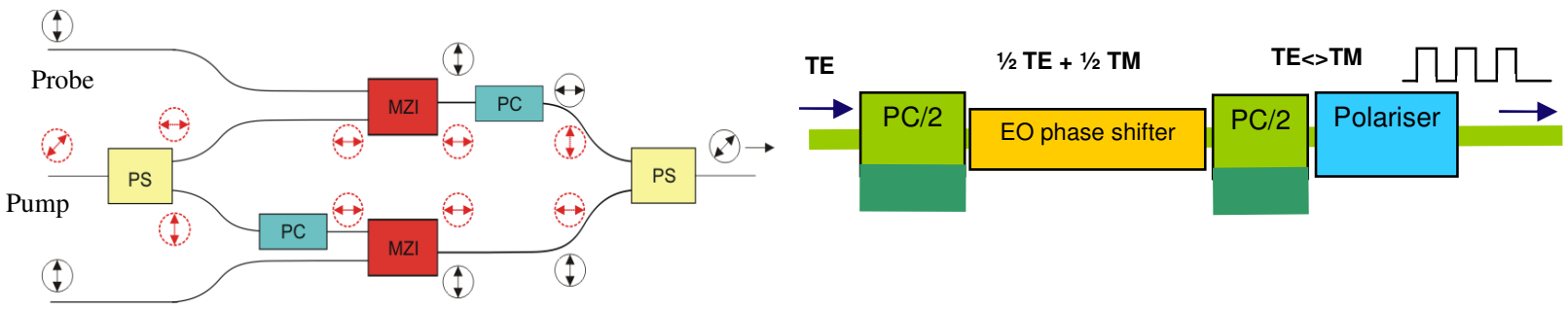

Fig. 5: POLARIS concept, including polarization splitters/combiners (PS), polarization converters (PC) and MachZehnder Interferometers (MZI).
Fig. 6: A polarization based MZI. The input and output couplers of the traditional MZI are replaced by partial polarization converters in the PMZI

The polarization was handled off chip with fiber optic components. The results show a suppression of the pump signal of $10 \mathrm{~dB}$, limited by the quality of the fiber optic polarization splitter.

c) Polarization Mach-Zehnder Interferometer (PMZI,fig. 6). In an MZI light is split over two branches, to control the phase of the two parts separately. Upon recombination the resulting interference depends on the phase difference. It is possible to propagate two independently phase controlled signals through one waveguide. The signals are in opposite polarization states. A partial polarization converter splits and combines the two polarized signals. This is a shorter version of the converter of fig.1. An example of a PMZI is given in fig.6. This is a modulator structure in which the Pockels-effect, only operating on the TE-polarization, is used to control the phase difference. I this way a smaller footprint and lower losses are obtained.

\section{Summary}

Integrated polarization manipulating devices, e.g., polarization converters, splitters and filters, make it possible to enhance functionality. Three examples are given, with polarization defining material function, signal identity and optical path within one waveguide.

\section{References}

[1] L.M. Augustin et al., "Short polarization converter optimized for active-passive integration.”, PTL, Vol. 19, no. 20 , p. 1673.

[2] L.M. Augustin et al., "A compact integrated polarization splitter/converter in InGaAsP- InP”, PTL, Vol. 19, no. 17, p.1286.

[3] A.A.M. Kok et al,"Short photonic crystal polarization filter in InGaAsP/InP", submitted to PTL.

[4] U. Khalique et al., "Polarization based integration scheme (POLIS) for active and passive components". Proc. ECIO'03., pp. 137-140.

[5] M.V. Kotlyar et al.,"Compact polarization converter in InP-based material, Opt. Exp., Vol. 13, Issue 13, pp. 5040-5045, 2005.

[6] B.M. Holmes et al., "Realization of low-loss monolithically integrated waveguide mode converters", PTL, Vol. 18, no. 1, p.43

[7] L.M. Augustin et al "Polarization based isolation in wavelength converter", Proc. ECOC 2004, pp. 612-613, September 2004. 